\title{
THERMIONIC CONVERTER EMITTER SUPPORT ARRANGEMENT
}

\author{
By: Daniel T. Allen USA \\ 1714 Kearsarge Road \\ La Jolla, CA 92037-3828
}

\section{DISCLAIMER}

This report was prepared as an account of work sponsored by an agency of the United States Government. Neither the United States Government nor any agency thereof, nor any of their employees, makes any warranty, express or implied, or assumes any legal liability or responsibility for the accuracy, completeness, or usefulness of any information, apparatus, product, or process disclosed, or represents that its use would not infringe privately owned rights. Reference herein to any specific commercial product, process, or service by trade name, trademark, manufacturer, or otherwise does not necessarily constitute or imply its endorsement, recommendation, or favoring by the United States Government or any agency thereof. The views and opinions of authors expressed herein do not necessarily state or reflect those of the United States Government or any agency thereof.

$\stackrel{0}{0}$

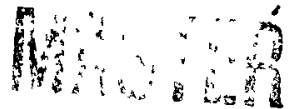




\section{DISCLAIMER}

This report was prepared as an account of work sponsored by an agency of the United States Government. Neither the United States Government nor any agency Thereof, nor any of their employees, makes any warranty, express or implied, or assumes any legal liability or responsibility for the accuracy, completeness, or usefulness of any information, apparatus, product, or process disclosed, or represents that its use would not infringe privately owned rights. Reference herein to any specific commercial product, process, or service by trade name, trademark, manufacturer, or otherwise does not necessarily constitute or imply its endorsement, recommendation, or favoring by the United States Government or any agency thereof. The views and opinions of authors expressed herein do not necessarily state or reflect those of the United States Government or any agency thereof. 


\section{DISCLAIMER}

Portions of this document may be illegible in electronic image products. Images are produced from the best available original document. 
THERMIONIC CONVERTER EMITTER

SUPPORT ARRANGEMENT

\section{BACKGROUND OF THE INVENTION:}

The Government has rights in this invention pursuant

5 to contract No. DE-AC03-86SF16298 awarded by the U.S. Department of Energy.

A common type of thermionic converter of a nuclear reactor includes a housing with a hollow collector, and an emitter containing nuclear fuel within the collector. The 10 emitter has one end fixed to the collector and a second or "free" end lying within but out of contact with the collector. The "free" end of the emitter must be supported against sideward movement against the collector while allowing it to move axially as it expands and contracts with 15 changing temperatures. The space between emitter and 
collector is filled with a cesium plasma in the normal mode of operation of common thermionic converters.

One prior type of support arrangement for the "free" end of the emitter, includes a spring structure formed by a 5 pair of Belleville washers. A forward end of the spring structure lies against the "free" end of the emitter and an opposite rear end lies against a support structure that is supported on the housing. The support structure was formed of ceramic. In tests it was found that as a result of extended

10 exposure to high temperatures, nuclear radiation, and the cesium plasma environment, the ceramic support structure cracked, discolored at its outside edge, and apparently disappeared in the center. These phenomena raise concern over contamination of the space between the emitter and collector

15 by loose ceramic particles, as well as shorting of the cell by the unsupported emitter second end touching the collector. A support arrangement which avoided these problems would be of considerable value.

\section{SUMMARY OF THE INVENTION}

In accordance with one embodiment of the present invention, a support arrangement is provided for supporting an end of an emitter that lies within a collector of a thermionic converter, to keep the emitter end away from the collector while allowing the emitter end to move axially with 
thermal contraction and expansion, which is of high reliability. The support arrangement includes a support structure with a peripheral portion mounted on the housing, and which supports a spring structure that holds the emitter

5 end. The support structure is a sandwich-like structure that includes a metal spring-engaging element, a metal main support whose peripheral portion is mounted on the housing, and a ceramic layer lying between them. The ceramic layer is bonded by hot pressing to the metal element and metal main

10 support. The ceramic layer electrically isolates the spring-supporting element from the main support while providing intimate physical contact with them to provide a good heat transfer path.

The spring structure includes a pair of

15 Belleville-type springs with their peripheries bonded. The holes in the Belleville springs can respectively engage the emitter and the spring-engaging element of the support structure. A wafer can lie loosely within the Belleville springs to minimize the passage of heat by thermal radiation 20 through the Belleville spring assembly.

The novel features of the invention are set forth with particularity in the appended claims. The invention will be best understood from the following description when read in conjunction with the accompanying drawings. 


\section{BRIEF DESCRIPTION OF THE DRAWINGS}

Fig. 1 is a side elevation view of a thermionic nuclear reactor fuel element comprised of three thermionic converters constructed in accordance with the present 5 invention.

Fig. 2 is a sectional view of the area $2-2$ of Fig. 1.

Fig. 3 is an exploded perspective view of the support arrangement of the converter of Fig. 2 .

Fig. 4 is a sectional" view of apparatus during an 10 early step in the fabrication of the support structure of Figs. 2 and 3 .

Fig. 5 is a sectional view of the apparatus of Fig. 4 during a later step of the fabrication method.

Fig. 6 is a sectional view of the apparatus of Fig. 5 15 during a later step in the fabrication method.

Fig. 7 is a sectional view of the final support structure.

\section{DESCRIPTION OF THE PREFERRED EMBODIMENT:}

Fig. 1 illustrates a thermionic nuclear reactor fuel 20 element 10 which includes a few thermionic converters such as 12, 14 lying within a housing 16. As shown in Fig. 2, the housing 16 holds within it a three-layer hollow collector 18 with a cylindrical hole 20 lying on an axis 22. The emitter assembly includes an emitter 24 lying concentric with the 
collector and carrying nuclear reactor fuel 26 in the form of ring-shaped pellets. As is shown for the other thermionic converter 14, the first or "lead" end 30 of each emitter assembly is fixed in position as by a metal transition ring

532 to the housing. The transition ring also serves to electrically connect each converter to the next in electrical series within the thermionic fuel element. The forward or "lead" direction is indicated by arrow F. As shown for emitter assembly 12, each emitter also has a second or rear 10 end 34 that is a free end in that it is not securely fixed to the housing. The free rear end 34 can move axially as the emitter expands and contracts, as it is heated and cooled. An annular space 36 is maintained between the emitter and collector. A support arrangement structure 40 supports the

15 free rear end of the emitter to keep it concentric with the collector and the axis 22 while allowing the free emitter end to move axially by a limited amount.

The support arrangement 40 includes a support structure 42 that is mounted on the transition ring 32 of the 20 housing, and a spring structure 44 that has a first or front end 46 that supports the free rear end of the emitter, and a second or rear end 48 that is supported on the support structure 42. As also shown in Fig. 3, the spring structure 44 includes a pair of Belleville-type springs 50, 52 that 25 have adjacent radially outer portions 54 that are joined 
together as by electron beam welding at 56. The inner portion 60 of each spring has a central hole 62, 64. As shown in Fig. 2, the central holes of the springs engage protrusions 70,72 on the rear end of the emitter and on the front end of the 5 support structure.

The support structure 42 includes three parts, these being a metal spring-engaging element 74 , a metal main support 76, and a ceramic layer 80 between them. The ceramic layer is bonded to the metal parts 74,76 to not only hold

10 the three parts of the support structure securely together, but also to enable the efficient conduction of heat. Heat is conducted from the spring-engaging element 74 to the main support 76 , thence through the transition ring 32 to the collector 18, through the housing 16, and into the reactor

15 coolant which lies outside of the thermionic fuel element. The ceramic layer 80 is electrically insulative to avoid the conduction of electricity between the metal parts 74,76 , which would electrically connect emitter and collector and short-circuit the thermionic converter.

High heat conduction through the bond between the ceramic layer 80 and its support 76 is useful to avoid a high absolute temperature of the ceramic and to avoid a large temperature difference, or large temperature gradient, between opposite surface portions of the ceramic layer and 25 its support that could cause damage to the more fragile 
ceramic. The Belleville springs of the spring structure 44 are thin and do not easily conduct heat from the emitter end 34 to the spring-engaging element 74 of the support structure. The metal main support 76 , whose periphery is

5 joined to the metal ring 32 that is in turn joined to the collector 18, tends to assume a temperature not much above that of the cooler collector 18. Thus, if the ceramic layer 80, which is by nature a heat insulative material, were not thermally bonded to the spring-engaging element 74 , the

10 ceramic layer would be at a temperature in between that of the hot emitter 34 and the colder collector. In addition, if there were alternative locations of good and poor conduction between the ceramic layer 80 and its support 76 , there would be high temperature gradients through the ceramic and warpage 15 and mechanical damage to the ceramic layer. A higher temperature of the ceramic would also accelerate undesired chemical reaction with its surroundings. The support structure is constructed to provide good bonding between parts at modest cost.

Figs. 4-7 illustrate steps in the fabrication of the support structure 42. As shown in Fig. 4, the fabrication process starts with a lower support element blank 82 out of which the main support element 76 is to be formed. A cavity 84 is formed in the blank and in the to-be-formed main 25 support element thereof, shown in phantom at 76 . The cavity 
is formed in a front face 86 of the blank. A forward direction is indicated by arrow $F$ and the axis of the part is shown at 22. The walls of the cavity 84 are formed so the middle 88 extends radially and an outer portion 90 extends in

5 a forward and radially-outward direction. The outer portion walls 90 extend at an angle $A$ of less than $45^{\circ}$ (about $10^{\circ}$ ) from a direct radially-outward direction. The walls of the cavity are then coated with a plurality of layers, or sublayers, of largely cerämic material such as alumina or

10 yttria forming the ceramic layer at 80 . The coating is accomplished by applying (as by plasma spraying) numerous graded sublayers, with a first sublayer consisting of, for example, $50 \%$ metal (niobium) and $50 \%$ ceramic (alumina or yttria), the next sublayers consisting of $25 \%$ metal and $75 \%$

15 ceramic, and the middle sublayers consisting entirely of ceramic. The next-to-last few sublayers consist of $25 \%$ metal and $75 \%$ ceramic, and the last sublayers consist of $50 \%$ metal and 50\% ceramic. The use of a combination of metal and ceramic in some sublayers is used to later obtain a cohesive

20 bond between opposite surface portions of the ceramic layer (or group of sublayers) and the metal parts, this process being known. After the entire ceramic layer has been deposited the apparatus has the appearance shown in Fig. 4. The ceramic layer has a radially-extending center portion $80 \mathrm{c}$ 25 and a radially-outwardly and forwardly extending outer 
portion, or cone-shaped portion, 80d.

The next step in the process is to machine away a face portion 92 of the structure of Fig. 4, along the line 94, to remove primarily metal of the blank 92, and to also 5 remove primarily forwardly-extending portions 96 of the ceramic layer and leave primarily radially extending portions. Fig. 5 shows the ceramic layer 80 and the lower blank $82 \mathrm{~A}$ after such machining. A next step, shown in Fig. 6, is to place an upper element blank 102 (which will form the

10 spring-engaging element, as will be described below) on the forward ceramic face of the layer 80. The upper blank 102 has a rear surface 100 which closely matches the front surface 102 of the ceramic layer. That is, the rear surface 100 has a flat middle region 100a and a cone-shaped outer region 100B,

15 which matches the front faces of the ceramic layer and of the lower blank 82. Then the parts are heated to a high temperature and pressed together in a known HIP (hot isostatic pressing) process which bonds the opposite faces of the ceramic layer 80 to the metal element 74 and the metal

20 blank 82. The fact that adjacent surfaces of all parts lie primarily in parallel planes, facilitates such hot pressing. After hot pressing, the periphery of the welded-together upper blank 102 and of the lower blank 82A are machined away. The lower blank $82 \mathrm{~A}$ is machined to the 25 final desired outer diameter of the main support element 76. 
Almost all of the upper blank 102 is machined away, with a small portion being left, whose contour is indicated at $74 x$, and which forms the spring-engaging element 74. Then, the front face of the sandwich formed by the three elements is

5 machined, as by a grinding wheel which grinds away that portion of the ceramic layer 80 lying forward of the line 106. The resultant support structure 42 is shown in Fig. 7. It can be seen that the front face 110 of the ceramic layer is even with adjacent front facès 112,114 of the element 74

10 and of the main support 76 . The front face 112 of element 74 lies around but rearward of the front face 116 of the element protrusion.

After the support structure $\mathbf{4 2}$ is formed, it can be attached to the already-formed spring structure 44 (Fig. 2).

15 The walls of the hole 64 in the lower Belleville-type spring can be electron beam welded to the metal spring-engaging element 74 to assure that they are maintained in a predetermined relative position. It may be noted that as the emitter becomes hot and expands, and the spring structure is

20 compressed, the lower Belleville spring 52 begins to flatten against the flat forward face of the support structure.

The operation of the spring structure can be enhanced in some cases by including a wafer 120 (Fig. 3) between the Belleville springs 50, 52. The wafer can be formed of a metal 25 material, and can be formed with edge portions 122,124 that 
extend at forward and rearward inclines. The wafer minimizes the passage of heat by thermal radiation from the emitter to the support structure.

Thus, the invention provides a thermionic converter

5 with a support arrangement for supporting the "free" or rearward end of an emitter on the housing in a highly reliable manner. The support arrangement includes a spring structure that holds the free end of the emitter concentric with the collector while allowing the emitter to expand and

10 contract axially, and a support structure that supports the rear end of the spring structure on the housing. The support structure includes a metal spring-engaging member that engages the rear end of the spring structure, a metal main support whose periphery is mounted to the housing, and a

15 ceramic layer between them. The ceramic layer is isostatically hot-press bonded to the rear surface of the spring engaging element and the front surface of the main support, to provide intimate contact for good heat conduction through the support structure, while providing electrical

20 insulation across the ceramic layer. The spring structure can include a pair of Belleville-type springs with adjacent peripheries bonded to each other and axially-spaced inner portions forming central holes. A wafer of larger diameter than either central hole can lie trapped between the 25 Belleville springs to block the passage of heat by thermal 
radiation through the spring structure.

Although particular embodiments of the invention have been described and illustrated herein, it is recognized that modifications and variations may readily occur to those

5 skilled in the art and consequently it is intended to cover such modifications and equivalents. 
Pages 13 thru 11 intentionally omitted 


\section{THERMIONIC CONVERTER EMITTER \\ SUPPORT ARRANGEMENT}

\section{ABSTRACT OF THE DISCLOSURE}

A support is provided for use in a thermionic converter to support an end of an emitter to keep it out of contact with a surrounding collector while allowing the

5 emitter end to move axially as its temperature changes. The emitter end (34, Fig. 2) is supported by a spring structure (44) that includes a pair of Belleville springs, and the spring structure is supported by a support structure (42) fixed to the housing that includes the collector. The support

10 structure is in the form of a sandwich with a small metal spring-engaging element (74) at the front end, a larger metal main support (76) at the rear end that is attached to the housing, and with a ceramic layer $(80)$ between them that is bonded by hot isostatic pressing to the metal element and 15 metal main support. The spring structure can include a loose wafer (120) captured between the Belleville springs. 
FIG. 1

FIG. 3
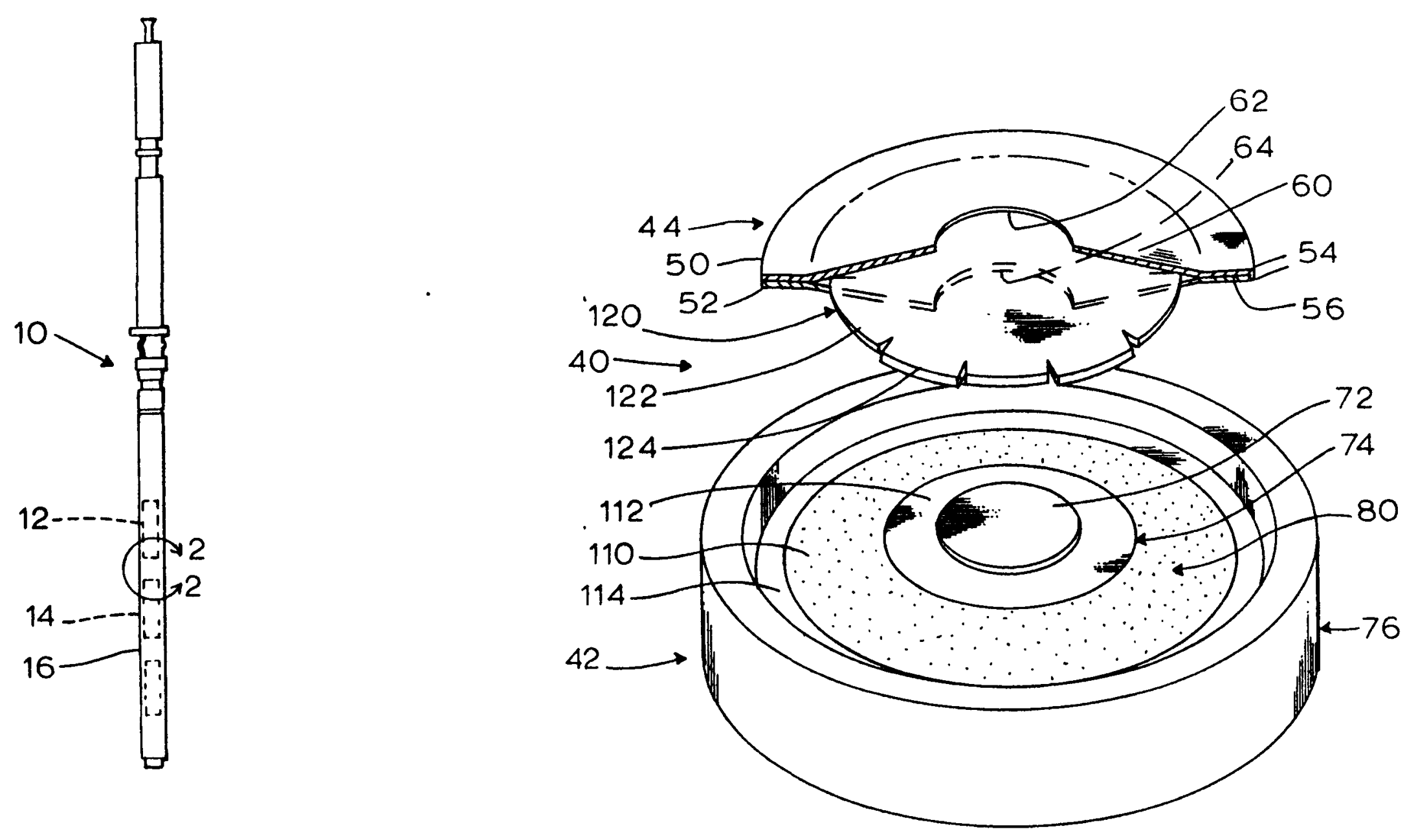


\section{FIG. 2}

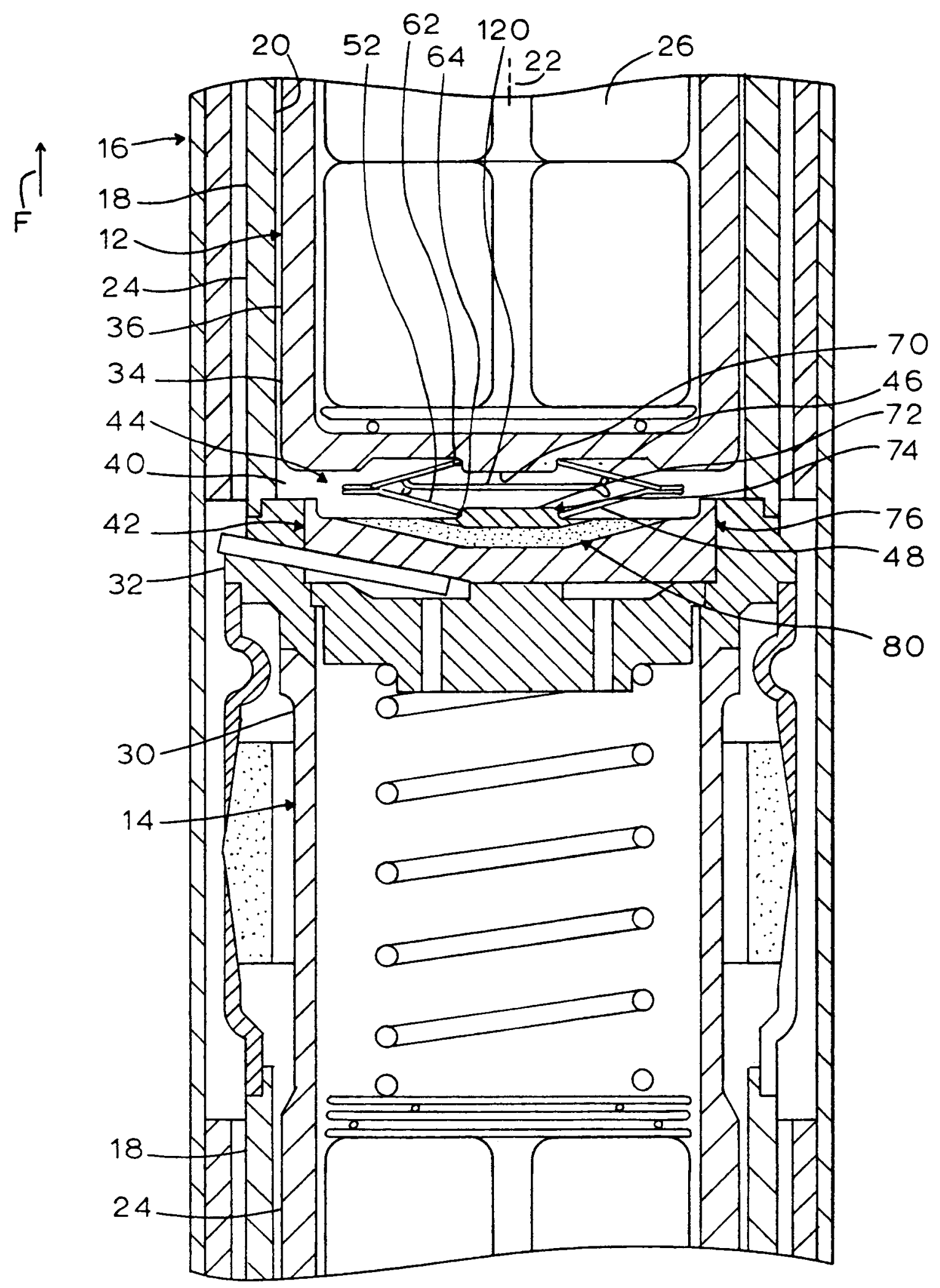


FIG. 4

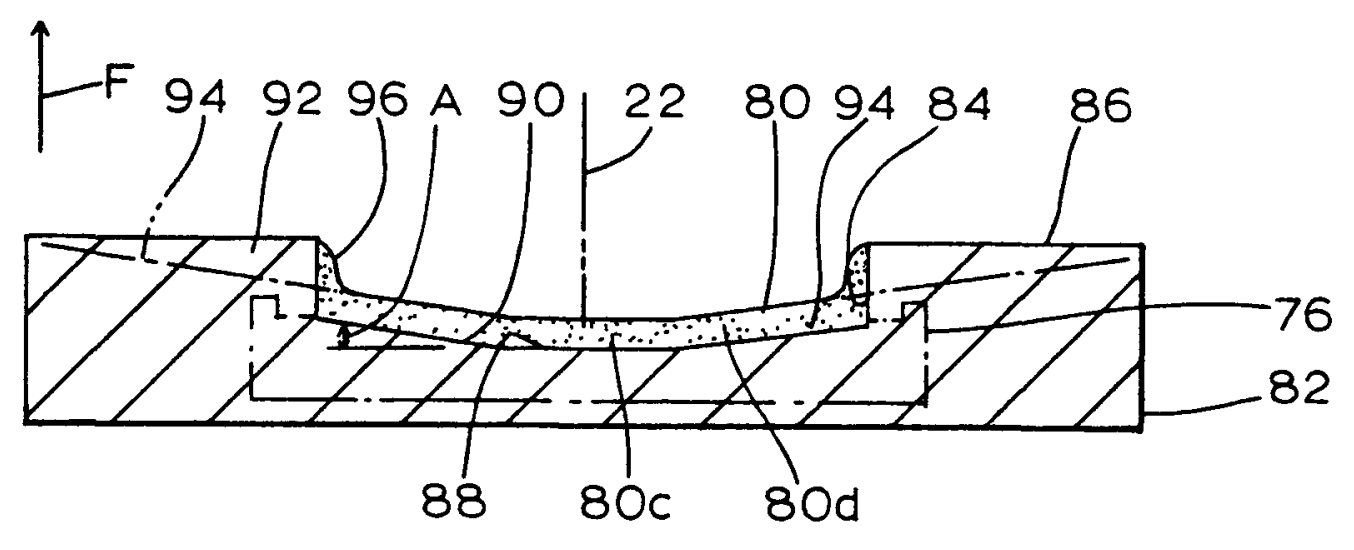

FIG. 5

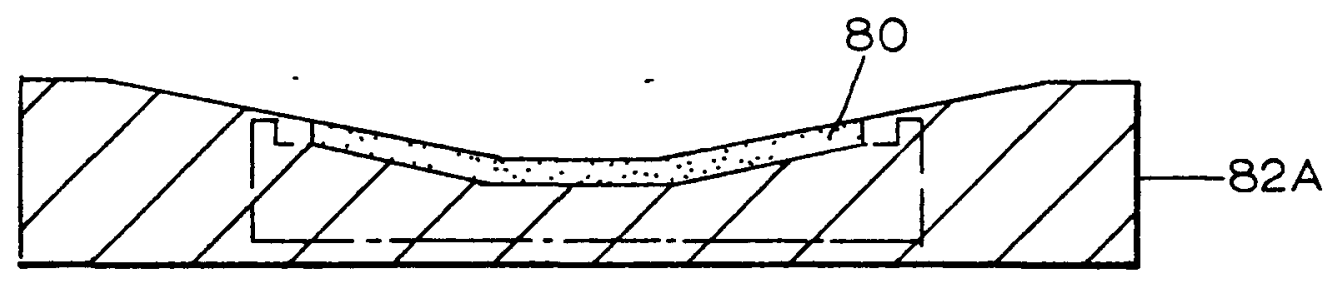

FIG. 6

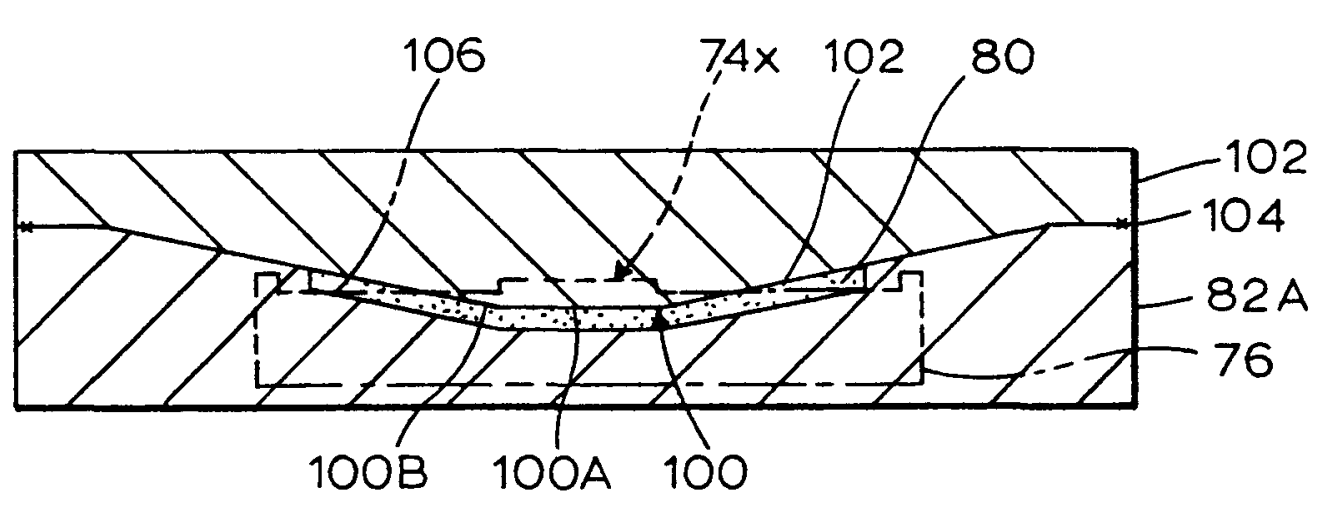

FIG. 7

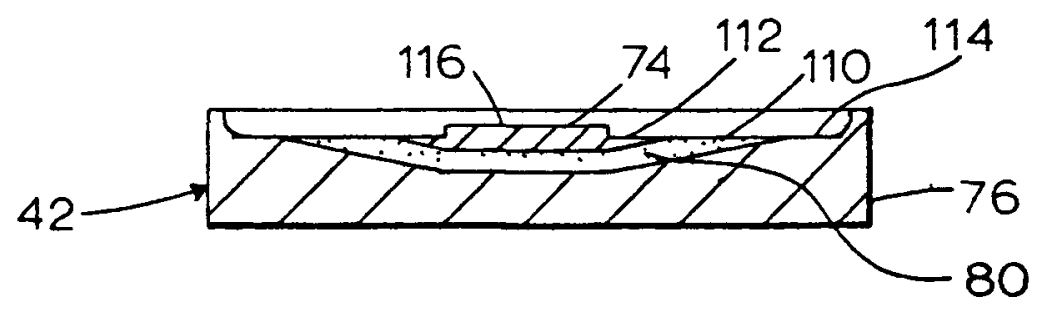

